\title{
Effective inhibition of MERS-CoV infection by resveratrol
}

\author{
Shih-Chao Lin ${ }^{1}$, Chi-Tang Ho ${ }^{2}$, Wen-Ho Chuo ${ }^{3}$, Shiming Li ${ }^{4}$, Tony T. Wang ${ }^{5^{*}}$ and Chi-Chen Lin ${ }^{1,6,7,8^{*}}$
}

\begin{abstract}
Background: Middle East Respiratory Syndrome coronavirus (MERS-CoV) is an emerging viral pathogen that causes severe morbidity and mortality. Up to date, there is no approved or licensed vaccine or antiviral medicines can be used to treat MERS-CoV-infected patients. Here, we analyzed the antiviral activities of resveratrol, a natural compound found in grape seeds and skin and in red wine, against MERS-CoV infection.

Methods: We performed MTT and neutral red uptake assays to assess the survival rates of MERS-infected Vero E6 cells. In addition, quantitative PCR, western blotting, and immunofluorescent assays determined the intracellular viral RNA and protein expression. For viral productivity, we utilized plaque assays to confirm the antiviral properties of resveratrol against MERS-CoV.
\end{abstract}

Results: Resveratrol significantly inhibited MERS-CoV infection and prolonged cellular survival after virus infection. We also found that the expression of nucleocapsid (N) protein essential for MERS-CoV replication was decreased after resveratrol treatment. Furthermore, resveratrol down-regulated the apoptosis induced by MERS-CoV in vitro. By consecutive administration of resveratrol, we were able to reduce the concentration of resveratrol while achieving inhibitory effectiveness against MERS-CoV.

Conclusion: In this study, we first demonstrated that resveratrol is a potent anti-MERS agent in vitro. We perceive that resveratrol can be a potential antiviral agent against MERS-CoV infection in the near future.

Keywords: MERS-CoV, Middle East Respiratory Syndrome Virus, Resveratrol, MERS-CoV virus infection, Inhibition

\section{Background}

Middle East Respiratory Syndrome (MERS) is a viral respiratory illness caused by a novel coronavirus (MERS-CoV) which was identified in Saudi Arabia in $2012[1,2]$. Up to December 2016, the mortality rate of MERS patients is 35.4\% with 652 deaths out of 1842 confirmed cases [3]. There is still no effective antiMERS medicine or vaccine commercially available in the market. One previous study showed that stilbene derivatives could contain antiviral activities against Severe Acute Respiratory Syndrome Coronavirus (SARS-CoV) [4]. As a result, we tested whether a natural stilbene derivative, resveratrol (trans-3, 5, 4'-trihydroxystilbene) inhibits the MERS-CoV infection in this study. Resveratrol

\footnotetext{
*Correspondence: tony.wang@sri.com; lincc@dragon.nchu.edu.tw ${ }^{5}$ Center for Infectious Diseases, Discovery Biology, SRI International, Harrisonburg, VA 22802, USA

${ }^{1}$ Ph.D. Program in Medical Biotechnology, National Chung Hsing University, Taichung, Taiwan

Full list of author information is available at the end of the article
}

exists widely in different plants, including grape (Vitis vinifera), Huzhang (Polygonum cuspidatum) and cranberry (Vaccinium macrocarpon)[5]. In the past, resveratrol was demonstrated to decrease the production of nitric oxide in tissue, and thereby reduce inflammation [6-8]. Resveratrol also acts as an antioxidant to remove free radicals $[9,10]$, thus restrains tumor growth [11] and even age-related diseases $[12,13]$. Resveratrol also inhibits STAT3 signaling pathway [14], the mTOR signaling [15], and the hedgehog signaling pathway [16]. Furthermore, resveratrol reportedly constrains infections caused by multiple pathogens, such as Helicobacter pylori [17], Staphylococcus aureus [18] or Toxoplasma gondii [19]. Interestingly, resveratrol has been demonstrated to exert antiviral effects against various viral infections, including Epstein-Barr virus (EBV) [20, 21], enterovirus 71 (EV71) [22], and herpes simplex virus (HSV) [23], as well as respiratory viral infections caused by influenza [24], respiratory syncytial 
virus (RSV) [25, 26], and rhinovirus [27]. However, it remains unknown whether resveratrol can inhibit MERS-CoV infection. In this study, we evaluated the antiviral effectiveness of resveratrol against MERS-CoV with an in vitro model.

\section{Methods}

Viral infection

Vero E6 cells (ATCC ${ }^{\oplus}$ Number: CRL-1586 ${ }^{\mathrm{m}}$ ) were planted on culture plates with $10 \%$ of fetal bovine serum (FBS) in DMEM for overnight before viral infection. MERS-CoV (HCoV-EMC/2012) was diluted to multiplicity of infection (M.O.I.) 0.1 with 2\% FBS/DMEM and replaced the culture media in plates.

\section{MTT assay}

MTT (3-(4,5-dimethylthiazol-2-yl)-2,5-diphenyltetrazolium bromide) can be reduced into formazan with purple color by cellular oxidoreductase as an indicator to access cell metabolism [28]. Briefly, Vero E6 cells were cultured on 96 well plates for overnight before administrating virus and resveratrol. After 48 hours incubation, supernatant was replaced with new culture medium and add $20 \mu \mathrm{L}$ of $5 \mathrm{mg} / \mathrm{mL}$ MTT solution in each well. Plates were incubated at $37{ }^{\circ} \mathrm{C}$ for 1 hour before removing MTT-containing medium. Extract formazan with MTT solvent, which consists of $4 \mathrm{mM} \mathrm{HCl}$ and $0.1 \%$ Nondet $\mathrm{P}-40$ (NP40) in isopropanol followed by measuring the level of purple formazan with ELISA reader (SpectraMax Plus 385, Molecular Devices ${ }^{\circ}$, USA) at wavelength $570 \mathrm{~nm}$. The readouts obtained from MTT assay were further normalized to the value of uninfected cells where the value was set to $100 \%$.

\section{Neural red uptake (NRU) assay}

Cells were cultured on 96-well plate and infected by virus with or without treatment of resveratrol for 48 hours before performing NRU assay. The culture medium were removed and each well was added to $100 \mu \mathrm{L}$ of $0.01 \%(\mathrm{w} / \mathrm{v})$ neutral red in DMEM followed by incubating the plates at $37{ }^{\circ} \mathrm{C}, 5 \% \mathrm{CO}_{2}$ for 1 hour. Neutral red/DMEM was removed and plates were washed twice with PBS. Neutral red dye was extracted with $100 \mu \mathrm{L} /$ well of Sorensen Citrate Buffer and the plates was gently shaken for $5 \mathrm{~min}$. The recovered neutral red dye was quantified by ELISA reader (SpectraMax Plus 385, Molecular Devices ${ }^{\circledR}$, USA) at wavelength $540 \mathrm{~nm}$. The results obtained were further normalized to the average readouts of tissue control groups where cell viability was set at $100 \%$.

\section{Plaque assay}

Vero E6 cells were planted in 12 well plates for overnight before conducting plaque assays. Viral samples were 10-fold serial diluted with MEM and added into cells. Cells were incubated with viral samples for one hour and rocked plates for every $15 \mathrm{~min}$. After incubation, the inoculums were removed and cells were washed in PBS. MEM containing 1.5\% agarose was then added to cells as overlay medium. Plates was incubated at $37^{\circ} \mathrm{C}$, $5 \% \mathrm{CO}_{2}$ for 3 days after overlay medium was solidified and fixed directly with $0.2 \%$ crystal violet solution before counting plaques.

\section{Immunofluorescent assay}

Vero E6 cells were seeded on 8-well chamber slides. Infected cells (treated with or without resveratrol) were first fixed in $4 \%$ paraformaldehyde for 15 minutes and then permeablized with $0.1 \%$ Triton X-100 for 10 mins. After 30 minutes blocking with $7.5 \%$ BSA at $37^{\circ} \mathrm{C}$, cells were immunostained with an anti-MERS-CoV N antibody (Sino Biological Inc., China) (1:500 dilution) at $4{ }^{\circ} \mathrm{C}$ overnight. After three washes with PBS, cells were then incubated with 1:1000 dilution of Alex Fluor 568 antirabbit secondary antibody (Thermo Fisher, USA) for 1 hour. Cells were then washed three times in PBS with DAPI being added during the second wash. MERS nucleocapsid expression was examined by confocal microscope (LSM-700, Zeiss, Germany). For intracellular staining of MERS nucleocapsid protein, the protocol is similar to immunofluorescent assay for confocal microscope except the blocking buffer was $10 \%$ horse serum in $0.05 \%$ PBStriton X100 and the secondary antibody was IRDye $800 \mathrm{CW}\left(\mathrm{Li}-\mathrm{Cor}^{\circ}\right)$ with 1: 10,000 dilution in PBS.

\section{Quantitative real-time PCR}

Total RNA samples of Vero E6 cells with or without MERS infection were isolated by RNeasy Mini kit (Qiagen ${ }^{\circ}$, Germany) according to the manufacturer's instructions. Reverse transcription and PCR amplification were carried out with iTaq ${ }^{\text {Tn }}$ Universal One-Step RT-qPCR kit (Bio-rad ${ }^{\oplus}$, USA) according to the manufacturer's instructions. Real-time PCR was conducted by using StepOnePlus $^{\text {Tix }}$ Real-Time PCR System (Appliedbiosystem ${ }^{\circ}$, USA) along with the following primer pairs: GAPDH-F: $5^{\prime}-\mathrm{G}$ AAGGTGAAGGTCGGAGTC-3', GAPDH-R: 5' -GAAG ATGGTGATGGGATTTC-3' [29], MERS-CoV-F: 5' -CC ACTACTCCCATTTCGTCAG MERS-CoV-R: 5'-CAGTATGTGTAGTGCGCATATAAGCA [30]. Each MERS RNA level defined as viral yield 1 was normalized with each GAPDH RNA level and relatively compared to MERS-CoV groups at 24 and 48 h.p.i. respectfully as relative RNA levels.

\section{Results}

Resveratrol reduced the cell death caused by MERS-CoV To investigate the anti-MERS-CoV effect of resveratrol, we directly treated MERS-CoV infected Vero E6 cells with different concentrations of resveratrol. Cells were 
infected with MERS-CoV at M.O.I. of 0.1. After 48 hours, we imaged the cellular morphology via microscopy and measured cell proliferation by MTT assay, cell viability by neutral red uptake (NRU) assay, and cytotoxicity levels by lactate dehydrogenase (LDH) assay. Resveratrol at 250 and $125 \mu \mathrm{M}$ seems to alleviate the monolayer destruction of the Vero E6 cells infected by MERS-CoV (Fig. 1). Results from MTT assays (Fig. 1a) and NRU assays (Fig. 1b) showed that resveratrol can reduce the cell death induced by MERS-CoV infection in the concentration range from $250-125 \mu \mathrm{M}$. Also, resveratrol-treated groups revealed less cytotoxicity by LDH assay after MERS-CoV infection (Fig. 1c) and the cytotoxicity profiles correlated well with that of cell proliferation and cell viability assays. To determine if the observed antiviral effect by resveratrol was due to its cytotoxicity, we performed LDH assay for resveratrol treatment only. Figure 1d showed that resveratrol caused limited cytotoxicity to Vero E6 cells. Even at the highest concentration of $250 \mu \mathrm{M}$, the cytotoxicity was no more than $25 \%$. In consistence, the cytotoxicity of MERS-CoV-infected cells was reduced by resveratrol treatment $(250 \mu \mathrm{M})$ to approximately $25 \%$ (Fig. 1c). Therefore, we conclude that resveratrol reduced the cell death caused by MERS-CoV infection.

\section{Resveratrol reduced the RNA expression and viral yield of} MERS-CoV

To determine if resveratrol directly inhibits MERS-CoV infection, we assessed the effects of resveratrol on MERS-CoV viral production at the RNA level. We collected cell samples with or without viral infection after resveratrol treatments at 24 and 48 hours post-infection (h.p.i). Extracted total RNA was subjected to quantitative real-time PCR to compare the relative MERS-CoV RNA levels. Shown in Fig. 2a, the MERS-CoV RNA levels in resveratrol-treated cells at concentrations of 250, 200, 150, 62.5, and $31.25 \mu \mathrm{M}$ were significantly lower than in MERS-CoV-infected cells at 24 h.p.i. However, the inhibitory effects of low concentrations of resveratrol, including 62.5 and $31.25 \mu \mathrm{M}$, diminished at 48 h.p.i. This data suggests that resveratrol treatment suppressed MERS-CoV RNA replication, although it requires relatively high concentrations of resveratrol to deliver persisted antiviral effects.

Next, we determined the infectious titer of MERS$\mathrm{CoV}$ after resveratrol treatments by plaque reduction assays. Data in Fig. 2b showed that MERS titers were significantly reduced by resveratrol treatment at 250, 200 and $150 \mu \mathrm{M}$ respectively, at 48 h.p.i. This result is consistent with those obtained from the quantitative realtime PCR at 48 h.p.i. In summary, these findings indicate that treatment of cells with resveratrol reduced the MERS-Cov RNA levels and infectious titers, which presumably accounted for the observed decrease in cell death.

\section{Resveratrol inhibited existing MERS-CoV infection}

Previous studies have shown that resveratrol exerted antiviral activities by blocking NF- $\mathrm{B}$ pathway $[22,30]$,
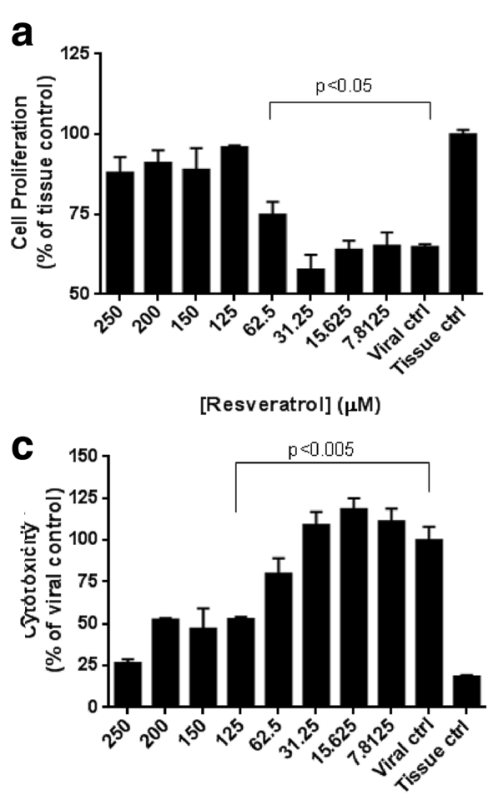

[Resveratrol] $(\mu \mathrm{M})$

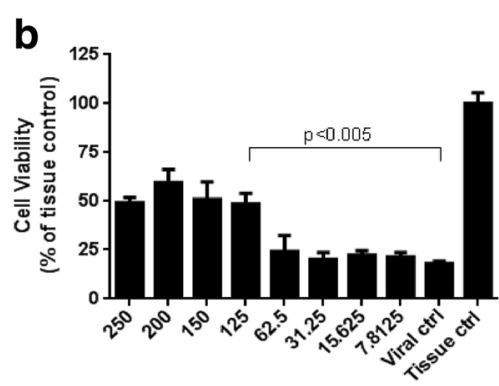

[Resveratrol] $(\mu \mathrm{M})$

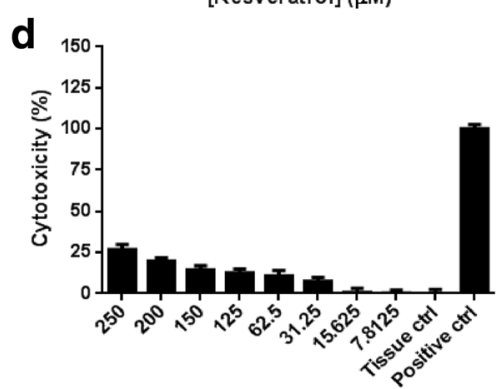

[Resveratrol] ( $\mu \mathrm{M})$

Fig. 1 Resveratrol reduced the cell death caused by MERS-CoV infection. Vero E6 cells were infected by MERS-CoV with M.O.I of 0.1 and treated with resveratrol for 48 hours. The level of cell viability was determined by (a) MTS assay (b) neutral red uptake assay, and (c) LDH assay. d Resveratrol itself caused limited cytotoxicity to Vero cells by LDH assay 

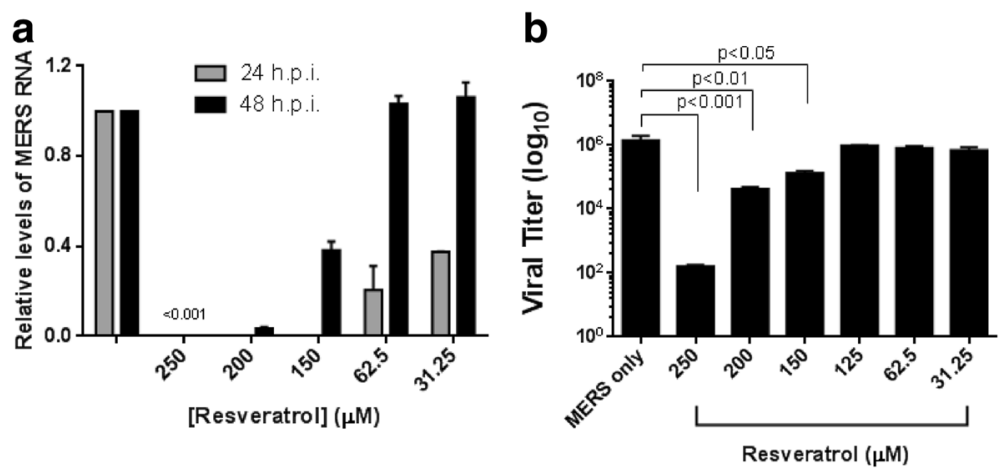

Fig. 2 Resveratrol decreased MERS-CoV RNA and viral plaques. a MERS RNA level was monitored at 24 and 48 h.p.i. by real-time PCR after resveratrol treatment. Relative RNA levels were determined by comparing MERS only groups at each time point. GAPDH RNA was used as an internal control. b Quantification of plaque reduction assay of MERS-CoV titer after treated with resveratrol from $250 \mu \mathrm{M}$ to $31.25 \mu \mathrm{M}$ for 48 hours

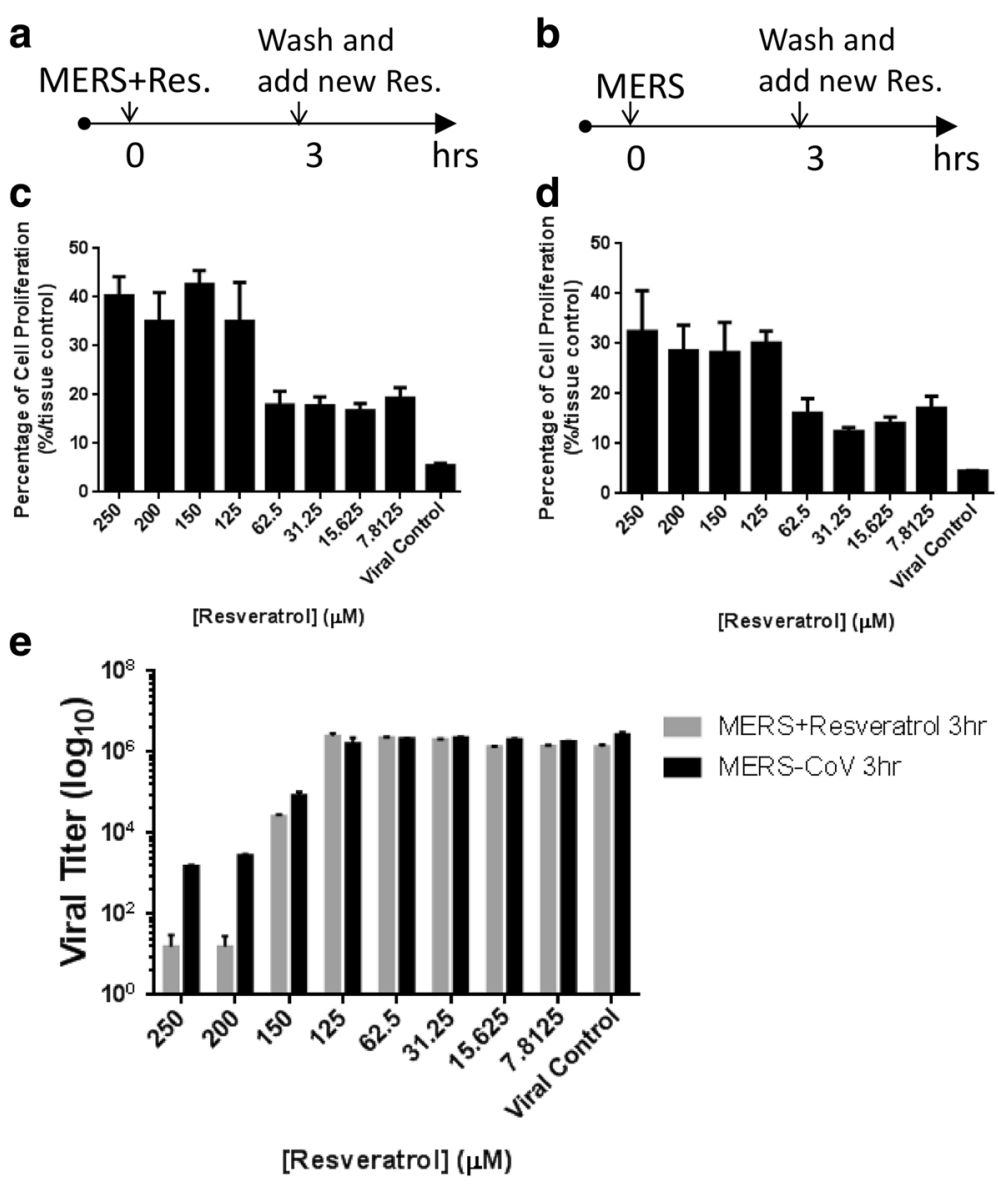

Fig. 3 Resveratrol inhibited the existing MERS infection. Resveratrol and MERS-CoV were simultaneously added into cells for first 3 hours before removing virus and adding new resveratrol for the rest incubating time (a). MERS-CoV infected Vero cells for first 3 hours before washed out and treated with resveratrol $(\mathbf{b})$. The trends of cell proliferation by MTT assays ( $\mathbf{c}$ and $\mathbf{d}$ ) and MERS-CoV titers by plaque assays (e) were similar, revealing resveratrol inhibited MERS viral yield even if existing MERS infection 
suggesting resveratrol has a broad spectrum of antiviral effects by down-regulating inflammatory signaling transduction. To determine whether resveratrol inhibits the entry or a post-entry step of MERS-Cov infection, we added resveratrol together with MERS-CoV immediately for 3 hours or after the infection has been initiated (Fig. 3a and b). We measured the cell proliferation (Fig. $3 \mathrm{c}$ and d) and determined the viral titers in the supernatants (Fig. 3e). The results demonstrated that even when resveratrol was given after MERS-CoV infection, it still reduced the viral titer. The same observations were made when cell proliferations and viral titers were measured, suggesting that resveratrol inhibits MERS-CoV infection after entry.
Resveratrol inhibited MERS-CoV nucleocapsid expression To corroborate our findings, we stained nuclecapsid $(\mathrm{N})$ protein of MERS-CoV after resveratrol treatments at 24 h.p.i and visualized the $\mathrm{N}$ protein distribution by confocal microscopy. Images shown in Fig. 4a demonstrated that $250 \mu \mathrm{M}$ of resveratrol eliminated the $\mathrm{N}$ protein fluorescent signal compared to control groups, while $150 \mu \mathrm{M}$ of resveratrol exhibited a limited decreasing of $\mathrm{N}$ protein signal. In order to elucidate whether the strength of $\mathrm{N}$ protein signal was correlated to the concentration of resveratrol, we performed intracellular staining of $\mathrm{N}$ protein in cells cultured in multiple well plates. MERS-infected Vero E6 cells were fixed and permeablized to facilitate anti-N primary antibody to access

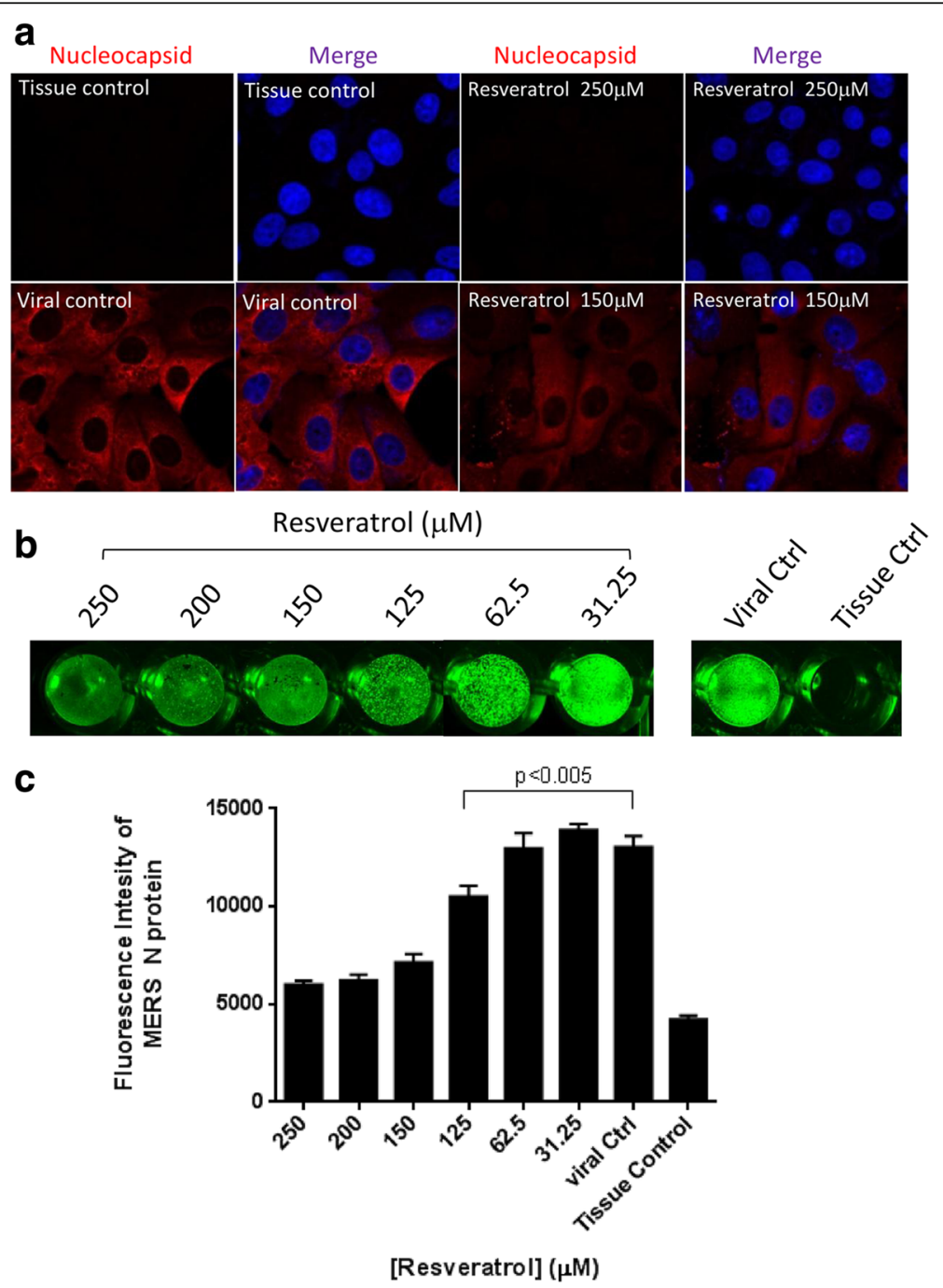

Fig. 4 Resveratrol reduced nucleocapsid expression of MERS-CoV. Vero E6 cells were infected by MERS-CoV (M.O.I. 0.1) and treated with resveratrol for 24 hours followed by $4 \%$ paraformaldehyde fixation for immunofluorescent assays. a Nucleocapsid expressions were examined with confocal microscope at 680x magnification. DAPI was used for nucleus staining. b Intracellular staining of MERS nucleocapsid expressions were visualized by Odyssey ${ }^{\circledast}$ CLx Imaging system. c Quantification results of fluorescent intensities of MERS nucleocapsid proteins were determined by Odyssey ${ }^{\circledR}$ CLx Imaging software 
the target protein and quantified the strength of fluorescence by Li-Cor imaging system (Fig. $4 \mathrm{~b}$ and c). The results showed that resveratrol remarkably inhibited MERS nucleocapsid protein translation in a dosedependent manner, especially in the concentration of 250 to $125 \mu \mathrm{M}$.

\section{Resveratrol inhibited Caspase 3 cleavage induced by MERS-CoV infection}

Apoptosis in different tissues during MERS-CoV infection has been widely documented [31, 32]. We therefore tested whether resveratrol is able to reduce the apoptosis induced by MERS-CoV. Due to the cleavage of Caspase 3 , an indicator of apoptosis, was reportedly elevated during MERS-CoV infection [33], we collected the cell lysates after MERS-CoV infection and resveratrol treatments at 24 and 48 h.p.i. and conducted western blotting to measure the Caspase 3 cleavage levels. The results (Fig. 5) show that the protein expression of the cleaved Caspase 3 significantly increased after MERS-CoV infection, confirming that MERS-CoV could cause cellular apoptosis. Interestingly, when resveratrol was added, the levels of Caspase 3 cleavage decreased. As the concentration of resveratrol went higher, the levels of Caspase 3 cleavage decreased in a dose-dependent manner (Fig. 5c). Our results suggest that resveratrol reduced the MERS$\mathrm{CoV}$-mediated apoptosis. Notably, resveratrol at $250 \mu \mathrm{M}$ did not lower the Caspase 3 cleavage to the same level, as did $200 \mu \mathrm{M}$ (Fig. 5a, c). Given to the cytotoxicity of resveratrol itself, this result is expected.

\section{Consecutively administration of resveratrol at lower concentrations inhibited MERS infection}

From the qPCR (Fig. 2a) and western blotting results (Fig. 5), we noticed that resveratrol at $62.5 \mu \mathrm{M}$ and below appeared to inhibit MERS-CoV within 24 hours but then lost effects at 48 h.p.i. The loss of inhibitory effects at $48 \mathrm{hrs}$ could due to the degradation of resveratrol in the media after such long period of incubation. Given the high dosages of resveratrol still has some cytotoxicity (Fig. 1e), lower dosages are more desirable to treat MERS-infected patients clinically. To explore the possibility of utilization of resveratrol at lower dosages, we added resveratrol consecutively (every $24 \mathrm{hrs}$ ) to MERS-infected cells at lower concentrations and evaluated the cell proliferation, cell viability, and cytotoxicity (Fig. 6). Interestingly, consecutive addition of resveratrol at $62.5 \mu \mathrm{M}$ but not $31.25 \mu \mathrm{M}$ or below partially rescued MERS-Cov-induced cell death (Fig. 6a-c) and lowered the production of infectious MERS-CoV by approximate tenfold (Fig. 6d), indicating resveratrol can inhibit MERS-CoV by administrating at lower dosages if given consecutively.
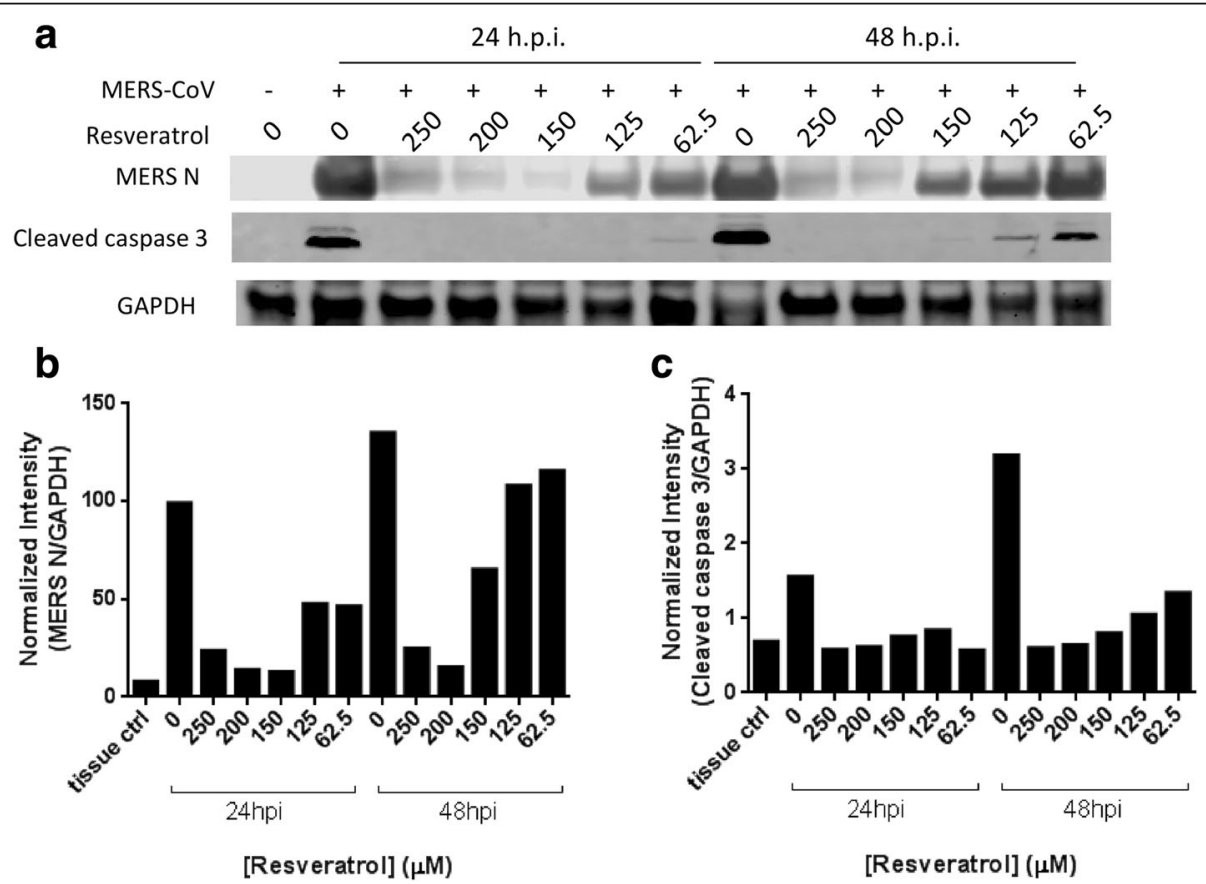

Fig. 5 Resveratrol reduced MERS-induced cell apoptosis. Vero E6 cells were infected by MERS-CoV at M.O.I. of 0.1 and treated with resveratrol for 24 and 48 hours before collecting protein lysates. a Protein expression levels of MERS nucleocapsid and cleaved caspase 3 were evaluated by western blotting. GAPDH was used as a loading control. $\mathbf{b}$ and $\mathbf{c}$ Protein expression levels were quantified and then normalized with GAPDH expression. MERS nucleocapsid as well as cleaved Caspase 3 expressions were reduced by resveratrol in a dose-dependent manner 

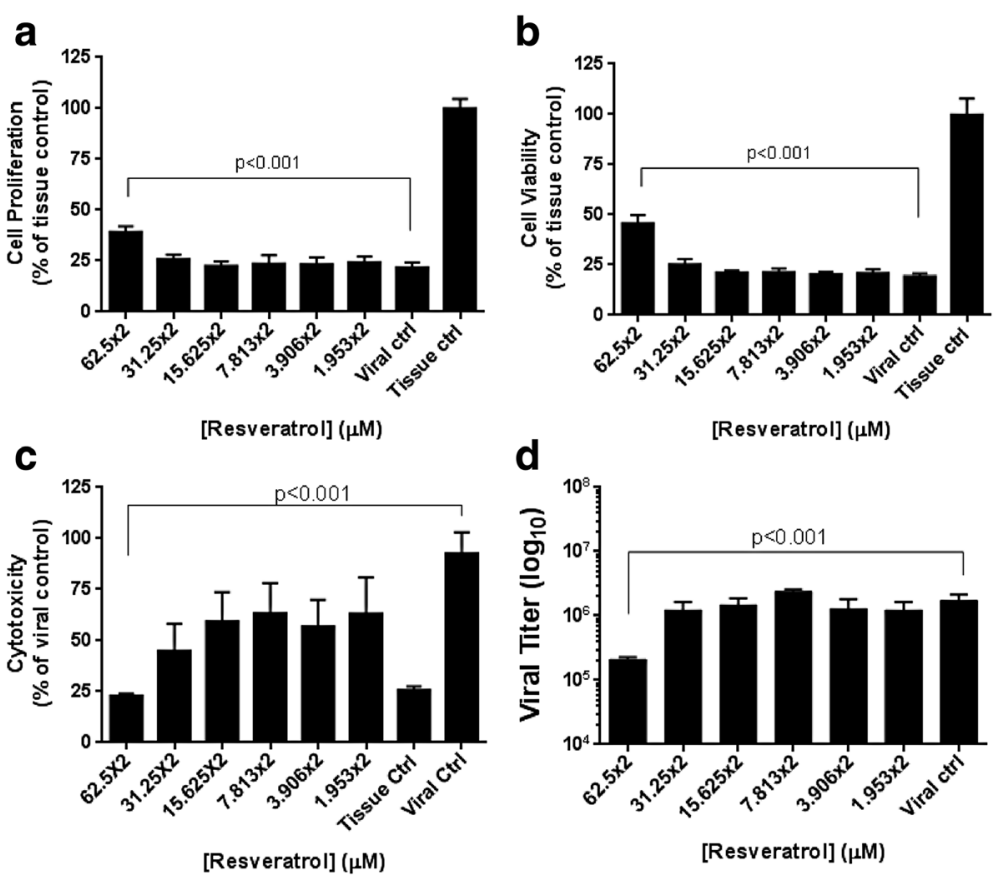

Fig. 6 Consecutively resveratrol administration inhibited MERS infection in a lower dosage. MERS-infected Vero E6 cells were treated with resveratrol in lower dosages every 24 hours. The cell proliferation by MTT assay (a), cell viability by NRU assay (b), cytotoxicity by LDH assay (c), and plaque assay (d) were utilized to measure the cell survival after 48 hours of MERS infection at M.O.I. of 0.1

\section{Resveratrol exhibited extended antiviral activities}

Furthermore, we tested the effects of resveratrol on another emerging positive-sense RNA virus, chikungunya virus. As shown in Fig. 7, resveratrol not only inhibited MERS-CoV viral production but also reduced the production of chikungunya virus at concentrations of 250 and $125 \mu \mathrm{M}$. Altogether, our data suggests that resveratrol might be a lead candidate for further pre-clinical assessments of antiviral activity for MERS-CoV and additional emerging RNA viruses.

\section{Discussion}

As an emerging human viral pathogen, MERS-CoV infection causes devastating diseases due to its high mortality. Therefore, it is urgent to develop vaccine or therapeutics. During the outbreak of Severe Acute Respiratory Syndrome (SARS) in 2002-2003, several antimicrobial agents were used to treat SARS-infected patients, including ribavirin, lopinavir/ritonavir, and type I interferon. However, most of the medication regimes showed no significant efficacy to SARS and came along with side effects, such as renal dysfunction or hemolytic anemia caused by ribavirin [34]. During the MERS-CoV epidemic, these treatments provided none or limited improvement in survival of patients and the efficacy remains unclear [35-37]. As a result, there is no effective remedial candidate during the MERS-CoV epidemic. In this study, we report the anti-MERS-CoV activities of resveratrol in vitro, providing evidence to support further detailed examinations of the potential clinical benefits for resveratrol in MERS-CoV infections.

We acknowledged that it is necessary to validate the anti-MERS efficacy of resveratrol in vivo. However, most of experimental animals, including rabbits, mice and ferrets, are asymptomatic after MERS infection [38-40]. Since the dipeptidyl peptidase 4 (DPP4) is a crucial receptor of MERS-CoV [41], we hypothesize that the human DPP4 expressed mice [42] could be a suitable model for examining the anti-MERS activity of resveratrol in the future.

Resveratrol itself has minor cytotoxicity even at high concentration of $250 \mu \mathrm{M}$, but it can be neglected comparing with the toxic levels caused by MERS-CoV infection, which were much greater than that of resveratrol itself. Considering the robust cell death caused by MERS-CoV, we think that resveratrol treatment remains a viable therapeutic strategy. In our study, we have shown that the resveratrol can be given either at high dosages up to $250 \mu \mathrm{M}$ or at a relatively low concentration, such as $62.5 \mu \mathrm{M}$ consecutively to treat MERS-CoVinfected cells.

In terms of the possible antiviral mechanisms for resveratrol, resveratrol has been reported to activate ERK1/ 2 signaling pathway [43] and promote cell proliferation and enhance SIR1 signaling [44], both of which are related to cellular survival and DNA repair in response to 


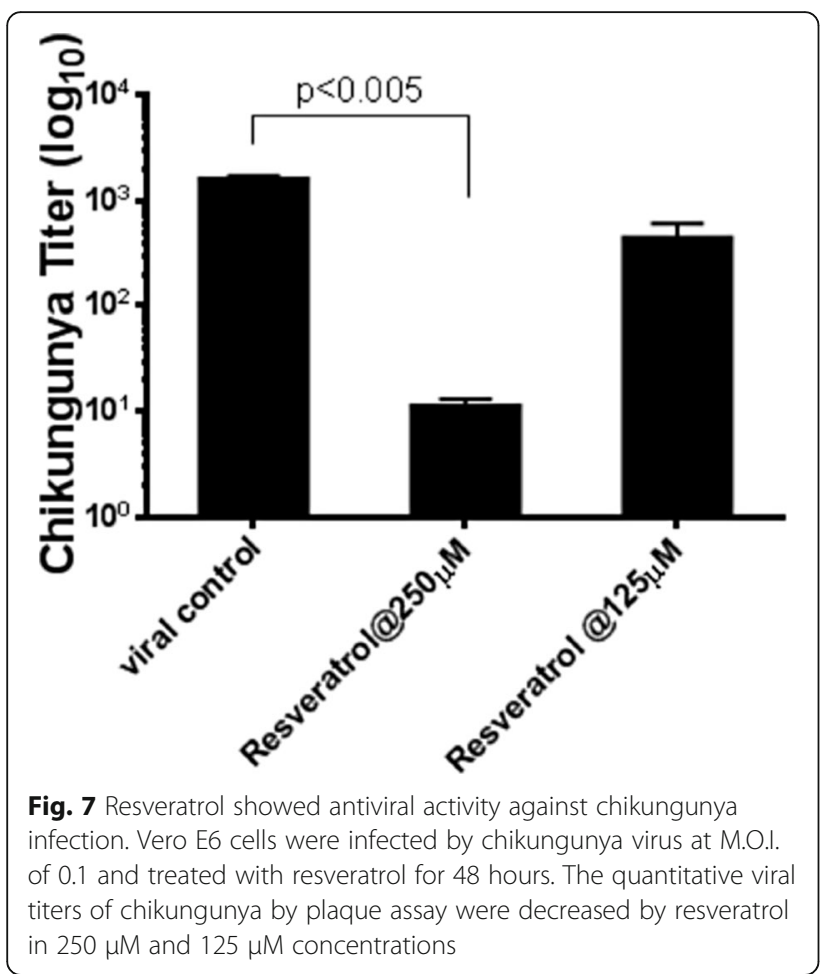

DNA damage $[45,46]$. On the other hand, resveratrol could counteract the MERS-CoV-induced apoptosis by down-regulating FGF-2 signaling $[47,48]$. In addition, MERS-CoV infection could lead to the production of inflammatory cytokines [49] whereas resveratrol may reduce the inflammation by interfering with the NF- $\mathrm{kB}$ pathway [50, 51]. In our study, the levels of cleaved caspase 3 were reduced by reseveratol after MERS-CoV infection. These changes may be results of direct inhibition of caspase 3 cleavage by resvertion of cell survival and the reduction of virus-induced apoptosis by resveratrol or inhibition of an upstream event that is required for caspase 3 cleavage. While the exact mechanism needs further investigation, the observed anti-MERS$\mathrm{CoV}$ effect appears to be a collective result of the promotion of cell survival and the reduction of virusinduced apoptosis by resveratrol.

\section{Conclusion}

In our study, we firmly found that resveratrol alone inhibits MERS-CoV infection. Future study will evaluate the potential synergy between resveratrol and other potential anti-MERS-CoV compounds to treat MERS-CoV infections.

\section{Abbreviations}

ERK1/2: Extracellular signal-regulated protein kinases 1 and 2; LDH: Lactate dehydrogenase; MERS-CoV: Middle East Respiratory Syndrome Coronavirus; NF-kB: Nuclear Factor-kappa B ; NRU: Neutral red uptake; SARS: Severe Acute Respiratory Syndrome

\section{Funding}

This research did not receive any specific grant from funding agencies in the public, commercial, or not-for-profit sectors.

\section{Availability of data and materials}

All the data supporting our findings is contained within the manuscript.

\section{Authors' contributions}

$\mathrm{CCL}$ and TTW designed the study, interpreted the results, and wrote the manuscript; SCL performed the experiments and participated in drafting the manuscript; CTH prepared the manuscript; WHC and SL provided necessary experimental materials for this study. All authors read and approved the final manuscript.

\section{Competing interests}

The authors declare that they have no competing interest.

\section{Consent for publication}

Not applicable.

Ethics approval and consent to participate

Not applicable.

\section{Author details \\ ${ }^{1}$ Ph.D. Program in Medical Biotechnology, National Chung Hsing University, Taichung, Taiwan. ${ }^{2}$ Department of Food Science, Rutgers University, New Brunswick, New Jersey, USA. ${ }^{3}$ Department of Pharmacy, Tajen University, Pingtung, Taiwan. ${ }^{4}$ Hubei Collaborative Innovation Center for the Characteristic Resources Exploitation of Dabie Mountains, Hubei Key Laboratory of Economic Forest Germplasm Improvement and Resources Comprehensive Utilization, Huanggang Normal University, Hubei, China. ${ }^{5}$ Center for Infectious Diseases, Discovery Biology, SRI International, Harrisonburg, VA 22802, USA. ${ }^{6}$ Department of Health and Nutrition, Asia University, Taichung, Taiwan. ${ }^{7}$ Department of Medical Research, China Medical University Hospital, Taichung, Taiwan. ${ }^{8}$ Department of Biomedical Sciences, National Chung Hsing University, 145 Xinda Rd., Taichung 40227, Taiwan.}

Received: 24 August 2016 Accepted: 8 February 2017

Published online: 13 February 2017

\section{References}

1. Corman VM, Eckerle I, Bleicker T, Zaki A, Landt O, Eschbach-Bludau M, van Boheemen S, Gopal R, Ballhause M, Bestebroer TM, et al. Detection of a novel human coronavirus by real-time reverse-transcription polymerase chain reaction. Euro Surveill. 2012;17(39). http://www.eurosurveillance.org/ ViewArticle.aspx? Articleld=20285.

2. Zaki AM, van Boheemen S, Bestebroer TM, Osterhaus AD, Fouchier RA. Isolation of a novel coronavirus from a man with pneumonia in Saudi Arabia. N Engl J Med. 2012;367(19):1814-20.

3. World Health Organization. WHO MERS-CoV Global Summary and risk assessment. 2016. http://www.who.int/emergencies/mers-cov/merssummary-2016.pdf (MERS-CoV). Accessed 15 Dec 2016.

4. Li YQ, Li ZL, Zhao WJ, Wen RX, Meng QW, Zeng Y. Synthesis of stilbene derivatives with inhibition of SARS coronavirus replication. Eur J Med Chem 2006;41(9):1084-9.

5. Riviere C, Pawlus AD, Merillon JM. Natural stilbenoids: distribution in the plant kingdom and chemotaxonomic interest in Vitaceae. Nat Prod Rep. 2012;29(11):1317-33

6. Wang LL, Shi DL, Gu HY, Zheng MZ, Hu J, Song XH, Shen YL, Chen YY. Resveratrol attenuates inflammatory hyperalgesia by inhibiting glial activation in mice spinal cords. Mol Med Rep. 2016;13(5):4051-57.

7. Kimbrough CW, Lakshmanan J, Matheson PJ, Woeste M, Gentile A, Benns MV, Zhang B, Smith JW, Harbrecht BG. Resveratrol decreases nitric oxide production by hepatocytes during inflammation. Surgery. 2015:158(4):1095-101. discussion 1101

8. Tsai SH, Lin-Shiau SY, Lin JK. Suppression of nitric oxide synthase and the down-regulation of the activation of NFkappaB in macrophages by resveratrol. Br J Pharmacol. 1999;126(3):673-80.

9. Li W, Cao L, Chen X, Lei J, Ma Q. Resveratrol inhibits hypoxia-driven ROS-induced invasive and migratory ability of pancreatic cancer cells 
via suppression of the Hedgehog signaling pathway. Oncol Rep. 2016;35(3):1718-26.

10. Jung KH, Lee JH, Thien Quach CH, Paik JY, Oh H, Park JW, Lee EJ, Moon SH, Lee KH. Resveratrol suppresses cancer cell glucose uptake by targeting reactive oxygen species-mediated hypoxia-inducible factor-1alpha activation. J Nucl Med. 2013;54(12):2161-7.

11. Zulueta A, Caretti A, Signorelli P, Ghidoni R. Resveratrol: A potential challenger against gastric cancer. World J Gastroenterol. 2015;21(37):10636-43.

12. Gliemann L, Nyberg M, Hellsten $Y$. Effects of exercise training and resveratrol on vascular health in aging. Free Radic Biol Med. 2016.

13. Toth P, Tarantini S, Tucsek Z, Ashpole NM, Sosnowska D, Gautam T, Ballabh $\mathrm{P}$, Koller A, Sonntag WE, Csiszar A, et al. Resveratrol treatment rescues neurovascular coupling in aged mice: role of improved cerebromicrovascular endothelial function and downregulation of $\mathrm{NADPH}$ oxidase. Am J Physiol Heart Circ Physiol. 2014;306(3):H299-308.

14. Baek SH, Ko JH, Lee H, Jung J, Kong M, Lee JW, Lee J, Chinnathambi A, Zayed ME, Alharbi SA, et al. Resveratrol inhibits STAT3 signaling pathway through the induction of SOCS-1: Role in apoptosis induction and radiosensitization in head and neck tumor cells. Phytomedicine. 2016;23(5):566-77.

15. Liu M, Liu F. Resveratrol inhibits mTOR signaling by targeting DEPTOR. Commun Integr Biol. 2011;4(4):382-4.

16. Gao Q, Yuan Y, Gan HZ, Peng Q. Resveratrol inhibits the hedgehog signaling pathway and epithelial-mesenchymal transition and suppresses gastric cancer invasion and metastasis. Oncol Lett. 2015;9(5):2381-7.

17. Zhang X, Jiang A, Qi B, Ma Z, Xiong Y, Dou J, Wang J. Resveratrol Protects against Helicobacter pylori-Associated Gastritis by Combating Oxidative Stress. Int J Mol Sci. 2015;16(11):27757-69.

18. Liu Y, Zhou J, Qu Y, Yang X, Shi G, Wang X, Hong Y, Drlica K, Zhao X. Resveratrol Antagonizes Antimicrobial Lethality and Stimulates Recovery of Bacterial Mutants. PLoS One. 2016;11(4):e0153023.

19. Bottari NB, Baldissera MD, Tonin AA, Rech VC, Alves $C B$, D'Avila F, Thome GR, Guarda NS, Moresco RN, Camillo G, et al. Synergistic effects of resveratrol (free and inclusion complex) and sulfamethoxazoletrimetropim treatment on pathology, oxidant/antioxidant status and behavior of mice infected with Toxoplasma gondii. Microb Pathog. 2016;95:166-74.

20. De Leo A, Arena G, Lacanna E, Oliviero G, Colavita F, Mattia E. Resveratrol inhibits Epstein Barr Virus lytic cycle in Burkitt's lymphoma cells by affecting multiple molecular targets. Antiviral Res. 2012;96(2):196-202.

21. Yiu CY, Chen SY, Chang LK, Chiu YF, Lin TP. Inhibitory effects of resveratrol on the Epstein-Barr virus lytic cycle. Molecules. 2010;15(10):7115-24.

22. Zhang L, Li Y, Gu Z, Wang Y, Shi M, Ji Y, Sun J, Xu X, Zhang L, Jiang J, et al. Resveratrol inhibits enterovirus 71 replication and pro-inflammatory cytokine secretion in rhabdosarcoma cells through blocking IKKs/NF-kappaB signaling pathway. PLoS One. 2015;10(2):e0116879.

23. Faith SA, Sweet TJ, Bailey E, Booth T, Docherty JJ. Resveratrol suppresses nuclear factor-kappaB in herpes simplex virus infected cells. Antiviral Res. 2006;72(3):242-51.

24. Lin CJ, Lin HJ, Chen TH, Hsu YA, Liu CS, Hwang GY, Wan L. Polygonum cuspidatum and its active components inhibit replication of the influenza virus through toll-like receptor 9-induced interferon beta expression. PLoS One. 2015;10(2):e0117602.

25. Zang N, Xie X, Deng Y, Wu S, Wang L, Peng C, Li S, Ni K, Luo Y, Liu E. Resveratrol-mediated gamma interferon reduction prevents airway inflammation and airway hyperresponsiveness in respiratory syncytial virusinfected immunocompromised mice. J Virol. 2011;85(24):13061-8.

26. Liu T, Zang N, Zhou N, Li W, Xie X, Deng Y, Ren L, Long X, Li S, Zhou L, et al. Resveratrol inhibits the TRIF-dependent pathway by upregulating sterile alpha and armadillo motif protein, contributing to anti-inflammatory effects after respiratory syncytial virus infection. J Virol. 2014;88(8):4229-36.

27. Mastromarino P, Capobianco D, Cannata F, Nardis C, Mattia E, De Leo A, Restignoli R, Francioso A, Mosca L. Resveratrol inhibits rhinovirus replication and expression of inflammatory mediators in nasal epithelia. Antiviral Res. 2015;123:15-21.

28. Mosmann T. Rapid colorimetric assay for cellular growth and survival: application to proliferation and cytotoxicity assays. J Immunol Methods. 1983;65(1-2):55-63.

29. Gunalan V, Mirazimi A, Tan YJ. A putative diacidic motif in the SARS-CoV ORF6 protein influences its subcellular localization and suppression of expression of co-transfected expression constructs. BMC Res Notes. 2011;4:446.
30. Furuse $\mathrm{Y}$, Okamoto M, Oshitani H. Conservation of nucleotide sequences for molecular diagnosis of Middle East respiratory syndrome coronavirus, 2015. Int J Infect Dis. 2015;40:25-7.

31. Chan RW, Chan MC, Agnihothram S, Chan LL, Kuok DI, Fong JH, Guan Y, Poon LL, Baric RS, Nicholls JM, et al. Tropism of and innate immune responses to the novel human betacoronavirus lineage $\mathrm{C}$ virus in human ex vivo respiratory organ cultures. J Virol. 2013;87(12):6604-14.

32. Hocke AC, Becher A, Knepper J, Peter A, Holland G, Tonnies M, Bauer TT, Schneider P, Neudecker J, Muth D, et al. Emerging human middle East respiratory syndrome coronavirus causes widespread infection and alveolar damage in human lungs. Am J Respir Crit Care Med. 2013;188(7):882-6.

33. Chu H, Zhou J, Wong BH, Li C, Chan JF, Cheng ZS, Yang D, Wang D, Lee AC, Li C, et al. Middle East Respiratory Syndrome Coronavirus Efficiently Infects Human Primary T Lymphocytes and Activates the Extrinsic and Intrinsic Apoptosis Pathways. J Infect Dis. 2016;213(6):904-14.

34. Stockman LJ, Bellamy R, Garner P. SARS: systematic review of treatment effects. PLoS Med. 2006;3(9):e343.

35. de Wit E, van Doremalen N, Falzarano D, Munster VJ. SARS and MERS: recent insights into emerging coronaviruses. Nat Rev Microbiol. 2016;14(8):523-34.

36. Omrani AS, Saad MM, Baig K, Bahloul A, Abdul-Matin M, Alaidaroos AY, Almakhlafi GA, Albarrak MM, Memish ZA, Albarrak AM. Ribavirin and interferon alfa-2a for severe Middle East respiratory syndrome coronavirus infection: a retrospective cohort study. Lancet Infect Dis. 2014;14(11):1090-5.

37. Shalhoub S, Farahat F, Al-Jiffri A, Simhairi R, Shamma O, Siddiqi N, Mushtaq A. IFN-alpha2a or IFN-beta1a in combination with ribavirin to treat Middle East respiratory syndrome coronavirus pneumonia: a retrospective study. J Antimicrob Chemother. 2015;70(7):2129-32.

38. Coleman CM, Matthews KL, Goicochea L, Frieman MB. Wild-type and innate immune-deficient mice are not susceptible to the Middle East respiratory syndrome coronavirus. J Gen Virol. 2014;95(Pt 2):408-12.

39. Haagmans BL, van den Brand JM, Provacia LB, Raj VS, Stittelaar K, Getu S, de Waal L, Bestebroer TM, van Amerongen G, Verjans GM, et al. Asymptomatic Middle East respiratory syndrome coronavirus infection in rabbits. J Virol. 2015;89(11):6131-5.

40. Raj VS, Smits SL, Provacia LB, van den Brand JM, Wiersma L, Ouwendijk WJ, Bestebroer TM, Spronken MI, van Amerongen G, Rottier PJ, et al. Adenosine deaminase acts as a natural antagonist for dipeptidyl peptidase 4-mediated entry of the Middle East respiratory syndrome coronavirus. J Virol. 2014; 88(3):1834-8

41. Raj VS, Mou H, Smits SL, Dekkers DH, Muller MA, Dijkman R, Muth D, Demmers JA, Zaki A, Fouchier RA, et al. Dipeptidyl peptidase 4 is a functional receptor for the emerging human coronavirus-EMC. Nature. 2013; 495(7440):251-4.

42. Zhao J, Li K, Wohlford-Lenane C, Agnihothram SS, Fett C, Zhao J, Gale Jr MJ, Baric RS, Enjuanes L, Gallagher T, et al. Rapid generation of a mouse model for Middle East respiratory syndrome. Proc Natl Acad Sci U S A. 2014;111(13):4970-5.

43. Klinge CM, Blankenship KA, Risinger KE, Bhatnagar S, Noisin EL, Sumanasekera WK, Zhao L, Brey DM, Keynton RS. Resveratrol and estradiol rapidly activate MAPK signaling through estrogen receptors alpha and beta in endothelial cells. J Biol Chem. 2005;280(9):7460-8.

44. Li S, Zhao G, Chen L, Ding Y, Lian J, Hong G, Lu Z. Resveratrol protects mice from paraquat-induced lung injury: The important role of SIRT1 and NRF2 antioxidant pathways. Mol Med Rep. 2016:13(2):1833-8.

45. Jeong J, Juhn K, Lee H, Kim SH, Min BH, Lee KM, Cho MH, Park GH, Lee KH. SIRT1 promotes DNA repair activity and deacetylation of Ku70. Exp Mol Med. 2007;39(1):8-13.

46. Kolthur-Seetharam U, Dantzer F, McBurney MW, de Murcia G, Sassone-Corsi P. Control of AIF-mediated cell death by the functional interplay of SIRT1 and PARP-1 in response to DNA damage. Cell Cycle. 2006;5(8):873-7.

47. Kuroyanagi G, Otsuka T, Yamamoto N, Matsushima-Nishiwaki R, Nakakami A, Mizutani J, Kozawa O, Tokuda H. Down-regulation by resveratrol of basic fibroblast growth factor-stimulated osteoprotegerin synthesis through suppression of Akt in osteoblasts. Int J Mol Sci. 2014;15(10):17886-900,

48. Yeung M-L, Yao Y, Jia L, Chan JFW, Chan K-H, Cheung K-F, Chen H, Poon VKM, Tsang AKL, To KKW, et al. MERS coronavirus induces apoptosis in kidney and lung by upregulating Smad7 and FGF2. Nature Microbiology. 2016;1:16004.

49. Zhou J, Chu H, Li C, Wong BH, Cheng ZS, Poon VK, Sun T, Lau CC, Wong KK, Chan JY, et al. Active replication of Middle East respiratory syndrome coronavirus and aberrant induction of inflammatory cytokines and chemokines in human macrophages: implications for pathogenesis. J Infect Dis. 2014;209(9):1331-42. 
50. Jakus PB, Kalman N, Antus C, Radnai B, Tucsek Z, Gallyas Jr F, Sumegi B, Veres B. TRAF6 is functional in inhibition of TLR4-mediated NF-kappaB activation by resveratrol. J Nutr Biochem. 2013;24(5):819-23.

51. Pan W, Yu H, Huang S, Zhu P. Resveratrol Protects against TNF-alphaInduced Injury in Human Umbilical Endothelial Cells through Promoting Sirtuin-1-Induced Repression of NF-KB and p38 MAPK. PLoS One. 2016;11(1): e0147034.

Submit your next manuscript to BioMed Central and we will help you at every step:

- We accept pre-submission inquiries

- Our selector tool helps you to find the most relevant journal

- We provide round the clock customer support

- Convenient online submission

- Thorough peer review

- Inclusion in PubMed and all major indexing services

- Maximum visibility for your research

Submit your manuscript at www.biomedcentral.com/submit 